\title{
Cost Effectiveness of Desarda Repair as Compared to Mesh Hernioplasty in Inguinal Hernia
}

\author{
Muhammad Rehman Gulzar, ${ }^{1}$ Muhammad Nasir, ${ }^{2}$ Shahbaz Ahmad, ${ }^{3}$ Muhammad Umar Farooq, ${ }^{4}$ Faiqa Aslam, ${ }^{5}$ Shuja Tahir 6 \\ 1,2,3Department of Surgery, Faisalabad Medical University, Faisalabad-Pakistan, 4,5,6Department of Surgery, DHQ Hospital, Faisalabad-Pakistan
}

\begin{abstract}
Background: Inguinal hernia repair is one of the most common surgical procedures performed. In the past many surgeons described their techniques of hernia repair including Bassini, Shouldice and McVay etc. However, Mesh repair by far has established its place as the gold standard treatment for inguinal hernias. In 2001, Dr. M.P. Desarda came up with his method using the transposition of external oblique sheath to strengthen the posterior wall of inguinal canal and obtained excellent results comparable to those of mesh repair. Keeping in view the advantages of this method we adopted this surgical procedure in our set up. Objective: To estimate the benefit of cost reduction in Desarda repair. Study Design: Observational Study. Settings: Surgical Department, DHQ Hospital Faisalabad Pakistan. Duration: One-year duration from January 2017 to December 2017. Methodology: In year 2017, a total of 413 patients were operated in surgical unit DHQ hospital Faisalabad using mesh repair. The record was obtained from the elective list register and record room. The data was entered on a special protocol Performa and analyzed on SPSS version 23. Results: A total number of 413 hernioplasties were performed during the study period and it was observed that 1.45 million PKR could have been saved in public sector health facility. Conclusion: By practicing the Desarda repair which gives comparable post-operative results to mesh repair, we can avoid the poly propylene mesh repair resulting in saving handsome budget in public sector hospitals of Pakistan.
\end{abstract}

Keywords: Desarda repair, Mesh hernioplasty, Cost effectiveness.

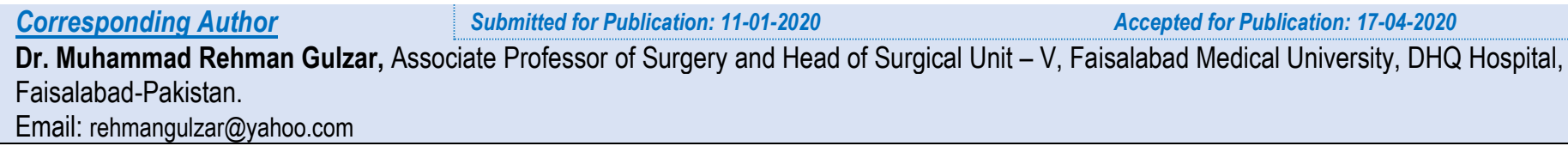

Citation: Gulzar MR, Nasir M, Ahmad S, Farooq MU, Aslam F, Tahir S. Cost Effectiveness of Desarda Repair as Compared to Mesh Hernioplasty in Inguinal Hernia. APMC 2020;14(2):112-4.

\section{DOI: $10.29054 / A P M C / 2020.838$}

\section{INTRODUCTION}

Inguinal hernia is a very common surgical problem suffered by humans. ${ }^{1}$ Surgery for hernia repair is one of the most common surgical procedures performed today. ${ }^{1}$ International data shows that in India, bassini repair cost was 2000 Indian rupees and Liechtenstein repair was 3500 indian rupees. ${ }^{5}$ In the past many surgeons described their techniques of hernia repair including Bassini, Shouldice and McVay etc. ${ }^{2}$

Mesh repair has lately become popular because of its relative simplicity and comparable results in different studies. Although foreign body sensation and risks of infection and seroma formation stand as significant complications related to this procedure. 6,7 However, surgeons all over the world are still in search of ideal operation for hernia.

In 2001 Dr. M. P. Desarda introduced a new technique of inguinal hernia repair using transposition of external oblique aponeurosis flap to strengthen the posterior wall of inguinal canal. ${ }^{3,4}$ This procedure is thought to be very close to an ideal operation for inguinal hernia with its simplicity, inexpensive nature and avoidance of use of foreign body.

Objective: The objective of this study is to estimate the benefit of cost reduction in Desarda repair.

\section{METHODOLOGY}

Study Design: Observational study.
Settings: The study was performed in Department of Surgery of DHQ Hospital Faisalabad in two wards named as surgical unit 4 and surgical unit 5.

Duration: A total duration of one year was taken as the study duration from January 1st, 2017 to December 31st, 2017.

Sample Technique: Non-probability convenient sampling.

Sample Size: Total 413 patients involved in the study.

Inclusion Criteria: All patients with inguinal hernia operated on elective list using mesh repair technique.

Exclusion Criteria: Patients younger than 15 years and those presenting in emergency with obstructed/strangulated hernias were excluded from the study.

Methods: A record of patients who underwent Mesh repair for their inguinal hernia was obtained and reviewed. The retail price per unit of mesh was obtained and total expenditure on mesh alone was calculated.

\section{RESULTS}

Total number of patients operated for inguinal hernia (Mesh hernioplasty) $=413$

Retail Price OF polypropylene Mesh (Ethicon) $6 \times 11 \mathrm{~cm}=3500$ PKR per mesh.

Total cost of mesh used in $2017=413 \times 3500=1445500 \mathrm{PKR}=$ 1.45 Million 


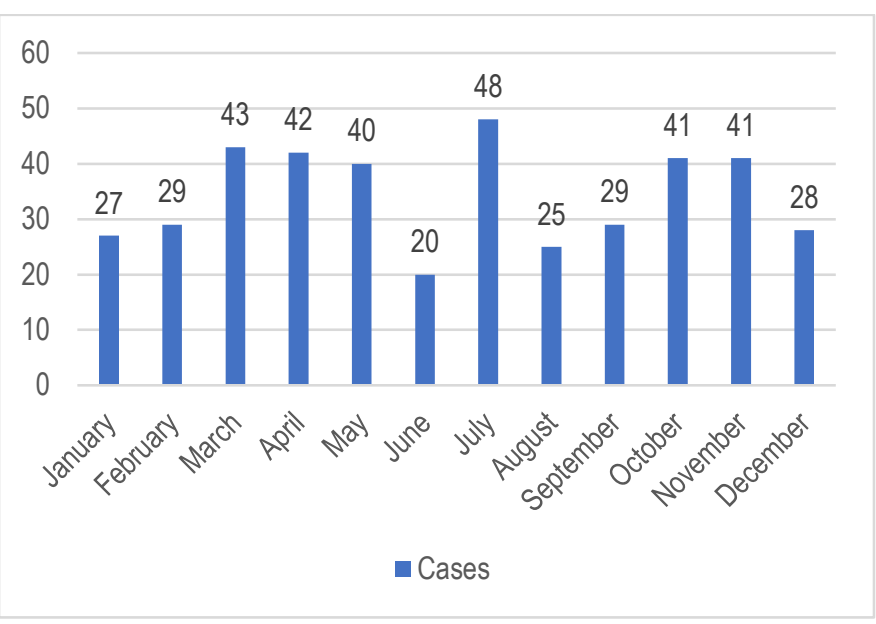

Figure 1: Month wise desarda repair cases $($ Total $=413$ )

\section{DISCUSSION}

Hernia repair is one of the most commonly performed operations worldwide. ${ }^{1} \mathrm{~A}$ number of methods has been described in literature dating back to remote past using native human tissues for repair. ${ }^{2}$ However, most were marred by poor results and high morbidity and mortality. Bassini ${ }^{2}$ was the first to grasp the importance of weakness of posterior wall of inguinal canal as an important factor contributing to hernia development. Based on his theory he described his technique of approximating the conjoined tendon with inguinal ligament. The results of his method were no short of excellent for his time. Later, many surgeons modified his technique including McVay, Shouldice. ${ }^{8,9}$

Lichtenstein popularized the use of prosthetic material called 'mesh'. 9,10 This method is now considered 'gold standard' since a large number of clinical trials did demonstrate its efficacy and reproducible results. However, the concerns of using foreign material, sexual dysfunction, infection and possibility of seroma formation linger on. ${ }^{6,7}$ Moreover, mesh is probably the most expensive of materials used in hernia repair especially for surgeons working in developing and underdeveloped countries under immense financial constraints. Therefore, surgeons the world over are continuously in search for tissue repair techniques that avoid the complications of mesh.

One such technique is Desarda repair. Hernia repair with Desarda technique is largely under trial and a lot of studies are being conducted on comparable postoperative results. Initial results are encouraging. ${ }^{11}$

Cost effectiveness is an understandable benefit of Desarda repair keeping in view the avoidance of mesh. However, nobody has delved into the impact of adopting this non-mesh method on saving the public money in poor countries. ${ }^{12}$

A study conducted in northern India Pune elaborated that a large amount of public funds can be saved by just not applying the mesh in hernia repair. ${ }^{4}$

In our study which is a single Centre experience, we observed that in busy centres where a lot of hernia repairs are being performed, a significant amount of public resources can be saved in millions. Widespread adoption of Desarda repair will result in saving billions of rupees that will be available to the healthcare system ready to be channeled elsewhere in the system.

\section{CONCLUSION}

Desarda repair is a useful addition to hernia repair techniques and can potentially reduce the cost of surgery dramatically and at the same time giving largely comparable results to mesh repair.

\section{LIMITATIONS}

Small sample size and single center study. Therefore, results cannot be generalized.

\section{SUGGESTIONS / RECOMMENDATIONS}

More large scale multicenter randomized trials are needed to validate the results and evaluate the true place of Desarda repair in this era dominated by mesh repair techniques.

\section{CONFLICT OF INTEREST / DISCLOSURE}

No conflict of interest is involved.

\section{ACKNOWLEDGEMENTS}

We acknowledge our supervisors and colleagues, for helping to conduct this study. Special thanks to the record keeper DHQ Hospital, Faisalabad Pakistan.

\section{REFERENCES}

1. Kingsnorth $A$, LeBlanc K. Hernias: inguinal and incisional. Lancet. 2003;362(9395):1561-71.

2. Beets GL, Oosterhuis KJ, Go PM, Baeten CG, Kootstra G. Longterm followup (12-15 years) of a randomized controlled trial comparing Bassini-Stetten, Shouldice, and high ligation with narrowing of the internal ring for primary inguinal hernia repair. J Am Coll Surg. 1997;185(4):352-7.

3. Desarda MP. Physiological repair of inguinal hernia: a new technique (study of 860 patients). Hernia. 2006;10(2):143-6.

4. Desarda MP. Inguinal herniorrhaphy with an undetached strip of external oblique aponeurosis: a new approach used in 400 patients. Eur J Surg. 2001;167(6):443-8.

5. Sinha SP, Sinha S. Mesh V/s Non-Mesh Hernia Repair: Comparison of Cost Effectiveness and Return to Work Among Agricultural Labourers. Int J Sci. 2013;1(3):100-6.

6. D'Amore L, Gossetti F, Vermeil V, Negro P. Long-term discomfort after plug and patch hernioplasty. Hernia. 2008;12(4):445-6.

7. LeBlanc KA. Complications associated with the plug-and-patch method of inguinal herniorrhaphy. Hernia. 2001;5(3):135-8.

8. Amato B, Moja L, Panico S, Persico G, Rispoli C, Rocco N, et al. Shouldice technique versus other open techniques for inguinal hernia repair. Cochrane Database Syst Rev. 2012;2012(4):CD001543.

9. Youssef T, El-Alfy K, Farid M. Randomized clinical trial of Desarda versus Lichtenstein repair for treatment of primary inguinal hernia. Int J Surg. 2015;20:28-34.

10. Szopinski J, Dabrowiecki S, Pierscinski S, Jackowski M, Jaworski $M$, Szuflet Z. Desarda versus Lichtenstein technique for primary inguinal hernia treatment: 3-year results of a randomized clinical trial. World J Surg. 2012;36(5):984-92. 
11. Desarda MP. New method of inguinal hernia repair: a new solution. ANZ J Surg. 2001;71(4):241-4.

12. Vale L, Grant A, McCormack K, Scott NW. Cost-effectiveness of alternative methods of surgical repair of inguinal hernia. Int $\mathrm{J}$ Technol Assess Health Care. 2004;20(2):192-200.

\begin{tabular}{|c|c|}
\hline \multicolumn{2}{|c|}{ AUTHORSHIP CONTRIBUTION } \\
\hline Muhammad Rehman Gulzar & $\begin{array}{l}\text { Chief operating surgeon, } \\
\text { Supervisor of the whole process, } \\
\text { Conceived the original idea of the } \\
\text { paper, Proof Reading }\end{array}$ \\
\hline Muhammad Nasir & Surgeon, Discussion \& References \\
\hline Shahbaz Ahmad & Proof Reading, References \\
\hline Muhammad Umar Farooq & Surgeon, Data Collection \\
\hline Faiqa Aslam & Data Collection and Statistical Work \\
\hline Shuja Tahir & $\begin{array}{l}\text { Data Collection and Statistical work, } \\
\text { Typing }\end{array}$ \\
\hline
\end{tabular}

